\title{
Daytime Energy Balance Relationship Over Rice Field
}

\author{
A. A. Mahmud, M. A. Baten, M. B. Khan and A. Miyata ${ }^{1}$
}

Department of Environmental Science, Bangladesh Agricultural University, Mymensingh

${ }^{1}$ National Institute of Agro-Environmental Science, Tsukuba, Japan

\begin{abstract}
The maximum and minimum values of $l E / R n$ (latent heat fluxes/Net radiation) ratio in Aman rice field were 0.63 $\mathrm{MJm}^{2}$, and $0.16 \mathrm{MJm}^{-2}$, respectively whereas the average value was $0.41 \mathrm{MJm}^{-2}$ during wet condition. $H$ (Sensible heat fluxes) was positive during the day with few fluctuations and the ratios of $H / R n$ fluctuated from $0.67 \mathrm{MJm}^{-2}$ to $0.22 \mathrm{MJm}^{-2}$ while the average value was $0.45 \mathrm{MJm}^{-2}$ and this phenomenon was due to available moisture availability in the Aman rice field. The maximum $G / R n$ ratio was $0.20 \mathrm{MJm}^{-2}$ while the minimum ratio was $0.09 \mathrm{MJm}^{-2}$ and their average value was $0.14 \mathrm{MJm}^{-2}$. The value of $G$ was considerably small due to the canopy architecture in Aman rice cropping system. In post Aman rice field, sensible heat flux density of the fallow rice field showed highest $25.66 \mathrm{MJm}^{-2}$. On an average, $H$ was $58.6 \%$ of the whole $R n$ while the minimum and maximum portions were $5.68 \%$ and maximum of $114.86 \%$, respectively in well irrigated fields. The measured average $H / R n$ ratio was $0.54 \mathrm{MJm}^{-2}$ in post Aman rice field while their maximum and minimum values were $0.79 \mathrm{MJm}^{-2}, 0.07$ $\mathrm{MJm}^{-2}$, respectively. The $l E / R n$ ratios ranged from $0.05 \mathrm{MJm}^{-2}$ to $0.76 \mathrm{MJm}^{-2}$ with an average value of $0.30 \mathrm{MJm}{ }^{-2}$. G/Rn accounted maximum $0.24 \mathrm{MJm}^{-2}$, minimum $0.07 \mathrm{MJm}^{-2}$ and on an average $0.16 \mathrm{MJm}^{-2}$ and $G$ was considerably larger than vegetative fields due to the less crop canopy architecture in post Aman rice fallow field. In Boro rice field variations in Rs mainly observed due to weather condition. H/Rn ratios from the rice field and observed that the maximum $0.88 \mathrm{MJm}^{-2}$, minimum 0.20 $\mathrm{MJm}^{-2}$ and on an average $0.49 \mathrm{MJm}^{-2}$, this phenomenon due to seasonal weather characteristics. The $l E / R n$ ratios in the Boro rice field observed maximum $0.60 \mathrm{MJm}^{-2}$, minimum $0.04 \mathrm{MJm}^{-2}$ and on an average $0.35 \mathrm{MJm}^{-2} . G$ accounted maximum $0.22 \mathrm{MJm}^{-2}$, minimum $0.08 \mathrm{MJm}^{-2}$ and on an average $0.16 \mathrm{MJm}^{-2}$ and $G$ was considerably small due to the canopy architecture Boro rice cropping system. In post Boro fallow rice field the maximum value of the ratio of $l E / R n$ was $0.82 \mathrm{MJm}^{-2}$ while the minimum value was $0.41 \mathrm{MJm}^{-2}$ with an average of $0.66 \mathrm{MJm}^{-2}$. The $l E / R n$ ratios exhibited the highest ratios among the all observation periods and due to more availability of water. The $H / R n$ ratios observed maximum $0.50 \mathrm{MJm}^{-2}$, minimum $0.12 \mathrm{MJm}^{-2}$ and on an average $0.25 \mathrm{MJm}^{-2}$. $G$ accounted maximum $0.14 \mathrm{MJm}^{-2}$, minimum $0.06 \mathrm{MJm}^{-2}$ and on an average $0.09 \mathrm{MJm}^{-2}$ and $G$ was considerably smaller than vegetative fields due to the less crop canopy architecture and much water availability in post Boro rice fallow field.
\end{abstract}

Key Word: Amon rice, Boro rice, Rn, H , lE, G

\section{Introduction}

The net radiative flux is a result of radiation balance at the surface. During the daytime it is usually dominated by the solar radiation and is almost always directed towards the surface, while at night the net radiation much weaker and directed away from the surface. As a result, the surface warms up during the day time, while it cools during the evening and night hours under clean sky (Arya, 2001). The direct or sensible heat flux at and above the surface arises as a result of the difference in the temperatures of the surface and the above. Actually, the temperature in the atmospheric surface layer varies continuously with height, with the magnitude of the vertical temperature gradient usually decreasing with height. The sensible heat flux is usually directed away from the surface during the daytime hours, when the surface is warmer than the air above, and vice versa during the evening and nighttime periods. Thus, the heat flux is down the average temperature gradient (Arya, 2001).The latent heat or water vapor flux is a result of evaporation, evapotranspiration, or condensation at the surface and is given by the product of the latent heat of evaporation or condensation and the rate of evaporation or condensation. The water vapor transfer through air does not involve any real heat exchange, except where phase changes between liquid water and vapor actually take place. Nevertheless, evaporation results in some cooling of the surface, which in the surface energy budget is represented by the latent heat flux from the surface to the above (Arya, 2001). The heat exchange through the ground medium is primarily due to conduction if the medium is soil, rock, or concrete. During the daytime, the surface receives radiative energy, which is partitioned into sensible and latent heat fluxes to the atmosphere and the heat flux to the sub-medium. Typically, $H$ (Sensible heat fluxes), $H_{\mathrm{L}}$ (Latent heat fluxes), and $H_{\mathrm{G}}$ (ground heat fluxes) are all positive over land surface during the day. At night, the surface loses energy by outgoing radiation, especially during clear or partially overcast conditions. This loss is compensated by gains of heat from air and soil media and, at times, from the latent heat of condensation released during the process of dew formation. So, the partitioning of solar energy near the surface on a short-term basis is an important aspect of the different type of energy exchanges involved in the earth-atmosphere-sun system. However, actual magnitudes of the various components of the surface energy budget depend on many factors, such as the type of surface and its characteristics (soil moisture, texture, vegetation, etc.), geographical location, month or season, time of 
day, and weather. Under special circumstances, e.g., when irrigating a field, $H$ and/or $H_{\mathrm{G}}$ may become negative and latent heat flux due to evaporative cooling of the surface may exceed the net radiation received at the surface (Arya, 2001). Due to seasonal variation air temperature, relative humidity, precipitation and wind speed also varies year to year. Solar radiation was higher May through July and the solar radiation in early spring and late summer tended to be rather lower. Long wave radiations over spring to autumn also exhibited similar seasonal pattern, however long wave radiations during summer and winter were larger. Evapotranspiration (ET) rates in autumn are low, despite the considerable precipitation. The climate warming greatly changed the partitioning of ET components over vegetative fields. Grass growth and Net ecosystem $\mathrm{CO}_{2}$ exchange receive strong influence from the moisture dynamics in the top 30-cm soil layer (Li et al., 2006). The role of stomatal control on the energy partitioning differs under various moisture conditions (Baldocchi et al., 2004). Therefore, it is very important to know which factors affect the portioning of solar energy over crop fields. In Bangladesh rice is grown under diverse ecological situation in three seasons namely Aus, Aman and Boro. Considering above views in mind, the present study was, therefore, undertaken with the following objectives:

I. To measure daytime the energy balance components $(R n=H+l E+G)$ over rice fields

\section{Materials and Methods}

\section{Description of the Site}

The study site, called MYM (three letter international code name for Asia Flux) is located in the paddy field of Bangladesh Agricultural University Farmland $\left(24.75^{\circ} \mathrm{N}, 90.5^{\circ} \mathrm{E}, 18 \mathrm{~m}\right.$ above sea level), $6 \mathrm{~km}$ to the south of Mymensingh town and $115 \mathrm{~km}$ to the north of Dhaka, the capital city of Bangladesh (Fig. 2.1). Magnetic Declination: $-00^{\circ} 20^{\prime}$ (negative west), 0.0'/year (2006/1/1); -00 24', 0.0'/year (2010/12/31) (NOAANGDC:http://www.ngdc.noaa.gov/geomagmo dels/struts/calcDeclination). This extensive field (about $78.28 \mathrm{ha}$ ) is used only for rice cultivation for a period of about 40 years. A weather yard and irrigation station and located near the study site. The usual cropping patterns are irrigated Boro riceFallow-rain fed Aman rice.

\section{Crop}

For this experiment, BRRI dhan 49 was used for Aman season and BRRI dhan 28 was used for Boro season.

\section{Soil}

MYM site soils are dark-gray non-calcareous floodplain type (UNDP and FAO, 1988). Study site soil possesses silty loam texture and low contents of organic matter. Topography of the soil at MYM site was low with fairly leveled surface.

\section{Climate}

In Mymensingh, both the summer and winter are relatively mild. The maximum and minimum temperatures as observed in April and January range between $33^{\circ} \mathrm{C}$ and $12^{\circ} \mathrm{C}$. Annual mean air temperature is 25.4 degree Celsius (1995-2008). Rainfall starts in May and continues up to September. Ninety-five per cent of the annual rainfall occurs during the monsoon. Annual precipitation: 2,252mm (1995-2008). Annual rainfall recorded in 1996 was 1620 millimeters. The highest humidity observed from July to September is around $94 \%$ and minimum is about $49 \%$ from January to April (BBS, 1998). MYM site annual mean temperature and totalized rainfall data were also collected for the past 14 years from Weather Yard, BAU, Mymensingh and presented in Appendix III and IV. Mymensingh seems to be less affected by natural calamities like flood, cyclone or drought as compared to other districts of the country.

\section{Management practices}

The experimental crops of rice were grown under recommended cultural practices at MYM site under the active supervision of Central Farm Authority at Bangladesh Agricultural University. This experiment was conducted without any influence what so ever on the rice paddy ecosystem to measure the status of energy balance.

\section{Flux Measurement Systems \\ Micrometeorological measurement}

These supporting data were sampled every 5 seconds using a CR23X data loggers supported by an AM25T multiplexer. Instruments used in micrometeorological measurement are presented in Table 1. Program used for collecting meteorological data.

Data are sampled and recorded using CR23X (Campbell) unless specified below.

1) A battery-driven data logger (KADEC-UP, Sapporo, Japan) is used for sampling and storage of pyranometer data

2) CR10X (Campbell) is used for a sampling and storage of TDR data.

\section{Calibration}

Every year instruments were calibrated with standard sensors specially the PAR sensors those are generally more affected due to long-term exposure at the site. 


\section{Data Collection and Mathematical Interpolation}

Data were collected intermittently mainly on the microclimatic parameters and plant attributes at different days after sowing and mathematically interpolated for additional analysis.

\section{Micrometeorological instrumentation}

Table 1. Measurement of meteorology at MYM site

\begin{tabular}{|c|c|c|}
\hline Observation items & Levels/depth/height & Instrument \\
\hline $\begin{array}{l}\text { Incoming and outgoing short-wave } \\
\text { radiation }\end{array}$ & $3.0 \mathrm{~m}$ & $\begin{array}{l}\text { Four component net radiometer (MR-40, Eko, Tokyo, Japan) } \\
\text { Four Component Radiometer (MR-40, Eko) }\end{array}$ \\
\hline $\begin{array}{l}\text { Incoming and outgoing long-wave } \\
\text { radiation }\end{array}$ & $3.0 \mathrm{~m}$ & Four Component Radiometer (MR-40, Eko) \\
\hline Net radiation & $3.0 \mathrm{~m}$ & Quantum sensor (LI-190, LI-COR) \\
\hline Incoming and outgoing PPFD & $2.95 \mathrm{~m}$ & \\
\hline Transmitted PPFD & & Quantum sensor (LI-191, LI-COR) \\
\hline Incoming short-wave radiation & Below canopy & Pyranometer (MS-62, Eko) ${ }^{1)}$ \\
\hline Air temperature & $3.0 \mathrm{~m}$ & \\
\hline Relative humidity & & Humicap(HMP45A, Vaisala, Finland) \\
\hline Soil temperature & $\begin{array}{l}1.65,2.95 \mathrm{~m} \\
1.65,2.95 \mathrm{~m}\end{array}$ & $\begin{array}{l}\text { Humicap (HMP } 45 \text { A, Vaisala, Finland) } \\
\text { Type-T thermocouple }\end{array}$ \\
\hline Soil heat flux & $0,0.05,0.1,0.2,0.4 \mathrm{~m}$ (five & \\
\hline Soil water content & $\begin{array}{l}\text { points) } \\
0.05 \mathrm{~m} \text { (three points) }\end{array}$ & $\begin{array}{l}\text { Heat flux plate (MF-180M, Eko) } \\
\text { TDR (TDR100, Campbell Scientific, USA) }{ }^{2)}\end{array}$ \\
\hline Field water level & $\begin{array}{l}0.05 \mathrm{~m} \text { (three points) } \\
0.1,0.2,0.3 \mathrm{~m}\end{array}$ & Capacitive water depth probe (model 6521, Unidata, \\
\hline Water temperature & Two points & Australia) \\
\hline Barometric pressure & $\begin{array}{l}0.02,0.05 \mathrm{~m} \\
-\end{array}$ & $\begin{array}{l}\text { Type-T thermocouple } \\
\text { Silicon capacitive pressure sensor (PTB210, Vaisala) }\end{array}$ \\
\hline
\end{tabular}

Precipitation $\quad-$ Tipping bucket rain gauge (Texas Instruments)

\section{Energy Balance}

The energy balance was computed from the following equation

$\boldsymbol{R}_{n} \downarrow+\boldsymbol{H} \uparrow+\boldsymbol{l E} \uparrow+\boldsymbol{G} \downarrow=\mathbf{O}$

Where, $R_{n}=$ canopy net radiation, $H=$ sensible heat flux, $l E=$ latent heat of vaporization and $G=$ ground heat flux, all with units of $\mathrm{Wm}^{-2}$. In the above stated equation, fluxes of $R_{n}$ and $G$ towards the surface were positive and towards the atmosphere were negative, while fluxes of $H$ and $l E$ towards the atmosphere were positive and vice-versa. The above equation can be rearranged as

$R_{n} \downarrow=H \uparrow+l E \uparrow+G \downarrow$

$R_{n} \downarrow-G \downarrow=H \uparrow+l E \uparrow$

\section{Bowen Ratio}

$(\beta)=Q_{H} / Q_{E}=\gamma\left(\Delta T_{a} / \Delta \mathbf{e}_{\mathrm{a}}\right)$

Where, $\gamma$ is the psychometric constant $\left(65 \mathrm{~Pa} \mathrm{~K}^{-1}\right), \mathrm{T}_{\mathrm{a}}$ is air temperature $(\mathrm{K})$, and $\mathrm{e}_{\mathrm{a}}$ is atmospheric vapor pressure $(\mathrm{Pa})$. When $\beta>1$, more energy is directed from the surface as sensible heat than as latent heat. In contrast, when $\beta<1$, the latent flux is the primary pathway for convective heat loss. Wet surfaces have a lower $\mathrm{b}$ than dry surfaces.
$\left(\Delta \mathrm{T}=\mathrm{T}_{1}-\mathrm{T}_{2}\right.$, Where $\mathrm{T}_{1}$ is the upper temperature and $\mathrm{T}_{2}$ is the down temperature; $\Delta \mathrm{e}=\mathrm{e}_{1}-\mathrm{e}_{2}$, where $\mathrm{e}_{1}$ is the upper atmospheric vapor pressure and $e_{2}$ is down atmospheric vapor pressure)

\section{Sensible Heat Flux}

From Bowen Ratio Energy Balance $H$ (sensible hat flux) can be calculated by using the following formula:

$H=\frac{R_{n}-G}{1+\beta^{-1}}$

\section{Latent Heat Flux}

From Bowen Ratio Energy Balance $l E$ (latent heat flux) can be calculated by using the following formula:

$$
l E=\frac{R_{n}-G}{1+\beta}
$$

\section{Ground Heat Flux}

The ground heat flux of the experimental plot was obtained directly from the Data logger output by using ground heat flow plates (EKO, MF-81). 


\section{Data Retrieval and Analysis}

The data received at 10 second intervals from the sensors on different micrometeorological parameters from the experimental site were primarily recorded by CR23X Data logger (Campbell Scientifics, USA). Then the output data from the Data logger as $30 \mathrm{~min}$ average was stored in a storage module (SM4M, Campbell Scientifics, and USA). The experimental raw data at $30 \mathrm{~min}$ intervals were retrieved from the storage module periodically for further averaging and mathematical interpolation. After obtaining $30 \mathrm{~min}$ average raw data from the field, these were then averaged again for $30 \mathrm{~min}$ intervals by using the program in Microsoft Excel. Data analyses were performed using MS Excel. Graphs were also prepared by the above mentioned software. As this kind of experiment only stresses on the monitoring of the climatic variables no replication possible and trends are obtained with average data streams those were collected during the intended span of this experiment. Since the initial data were recorded as 10 sec intervals which were $30 \mathrm{~min}$ averaged, so statistical errors were too minimum and hence neglected.

\section{Results and Discussion}

The experiment was carried out from August 2010 to July 2011 over two rice growing seasons (Aman season 2010 and Boro season 1011) and the post fallow periods (Post Aman Fallow 2010 and Post Boro Fallow 2011). During the experimental periods observations were made on thirty clear days. The observations include Energy Balance Bowen-ratio measurements system (net radiation, soil heat flux, temperature and vapor pressure gradient), relative humidity, wine speed and solar radiation.

\section{Vegetation}

\section{Vegetative fields}

The mean flux partitioning characteristics of fluxes over rice field were influenced by vegetation. Sensible heat flux $(H)$, latent heat flux $(l E)$ and ground heat flux $(G)$ followed the pattern of global radiation throughout the year. Sensible heat flux $(H)$, latent heat flux $(l E)$ and ground heat flux $(G)$ of Boro season greatly fluctuated than the Aman season. This phenomenon observed due to seasonal variations. During both season the soil and canopy experienced a shift form dry to wet due to irrigation or rain events. Due to irrigation or rain input soil moisture increased, both $H$ and $l E$ dominated the daytime energy partitioning. In Aman season availability of soil moisture is higher due to frequent precipitations throughout the seasons as a result latent heat flux accounted higher than the Boro season and dominance of ground heat flux observed in Boro seasons due to canopy architecture and clear weather.

\section{Bare fields}

On post Boro fallow fields significant differences of $l E$ observed than the post Aman fallow field due to more precipitations. In post Aman fallow field dominance of sensible heat flux $(H)$ was observed than the post Boro fallow fields. Ground heat flux $(G)$ showed significant fluctuation and showed negative values in post Boro rice field than the post Aman fallow field. This phenomenon was observed due to presence of higher water table and also the presence of various types of weeds.

\section{Energy balance relationship over rice field Daytime energy balance relationship over rice field on Aman 2010}

Daytime energy balance components over Aman rice field of the experimental plot on different growth stages of rice have been shown in Table 2. There was variation in $R s$ mainly due to weather conditions. $R n$ was varied mainly due to differences in surface conditions (Baten and Kon, 1997). Latent heat flux accounted for a large portion of $R n$ as it was expected from the sufficient soil water content. Latent heat flux density of the mature rice field before rice harvest showed highest $18.81 \mathrm{MJm}^{-2}$. On an average, $l E$ was $40.91 \%$ of the whole $R n$ of the rice field (Table 4 ). In rice field it also observed that a minimum $l E$ of 15.34 $\%$ and maximum of $88.53 \%$ in well irrigated fields. There also measured $l E / R n$ ratios from the rice field and observed maximum $0.63 \mathrm{MJm}^{-2}$, minimum 0.16 $\mathrm{MJm}^{-2}$ and on an average $0.41 \mathrm{MJm}^{-2}$ when soil surface was wet and water was not limiting on Aman 2010 season. $H$ was positive during the day with few fluctuations and $H / R n$ ratios from the rice field observed that the maximum $0.67 \mathrm{MJm}^{-2}$, minimum $0.22 \mathrm{MJm}^{-2}$ and on an average $0.45 \mathrm{MJm}^{-2}$ and this phenomenon due to less moisture availability in the Aman rice field. $G / R n$ ratios from the rice field was maximum $0.20 \mathrm{MJm}^{-2}$, minimum $0.09 \mathrm{MJm}^{-2}$ and on an average $0.14 \mathrm{MJm}^{-2}$ and $\mathrm{G}$ was considerably small due to the canopy architecture of Aman rice cropping system. 
Table 2: Day time (6:00h to 18:00h) energy balance of different growth stages of Aman rice field. It includes different weather parameters (Air temperature, relative humidity and wind speed), incoming solar radiations $(R s)$, net radiations $(R n)$, latent heat fluxes $(l E)$, sensible heat fluxes $(H)$ and soil heat fluxes $(G)$. Ratios of latent heat fluxes and soil heat fluxes to net radiation are also included.

\begin{tabular}{|c|c|c|c|c|c|c|c|c|c|c|}
\hline \multirow[t]{2}{*}{ Seasons } & \multirow[t]{2}{*}{ Field Status } & \multirow[t]{2}{*}{ DOY } & $R s$ & $R n$ & $l E$ & $H$ & $G$ & $l E / R n$ & $H / R n$ & G/Rn \\
\hline & & & \multicolumn{8}{|c|}{$\mathrm{MJ} / \mathrm{m}^{2}$} \\
\hline \multirow{9}{*}{ 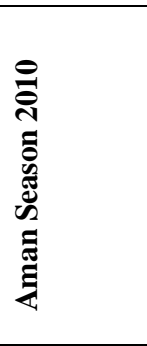 } & \multirow{3}{*}{$\begin{array}{l}\text { Early growth } \\
\text { stage }\end{array}$} & 231 & 19.08 & 15.51 & 8.76 & 4.40 & 2.36 & 0.56 & 0.28 & 0.15 \\
\hline & & 232 & 16.40 & 13.47 & 6.78 & 3.97 & 2.71 & 0.50 & 0.30 & 0.20 \\
\hline & & 233 & 20.82 & 16.25 & 3.26 & 10.09 & 2.89 & 0.20 & 0.62 & 0.18 \\
\hline & \multirow{3}{*}{$\begin{array}{l}\text { Full growth } \\
\text { stage }\end{array}$} & 262 & 23.18 & 21.14 & 5.23 & 13.39 & 2.52 & 0.25 & 0.63 & 0.12 \\
\hline & & 263 & 23.44 & 21.02 & 3.33 & 14.13 & 3.57 & 0.16 & $\begin{array}{l}0.67 \\
\end{array}$ & 0.17 \\
\hline & & 264 & 16.92 & 14.55 & 7.71 & 5.05 & 1.80 & 0.53 & 0.35 & 0.12 \\
\hline & \multirow{3}{*}{$\begin{array}{c}\text { Mature crop } \\
\text { Before } \\
\text { Harvesting }\end{array}$} & 292 & 35.91 & 31.94 & 18.81 & 10.00 & 3.13 & 0.59 & 0.31 & 0.10 \\
\hline & & 293 & 19.52 & 25.93 & 16.46 & 5.68 & 3.79 & 0.63 & 0.22 & 0.15 \\
\hline & & 294 & 38.57 & 31.34 & 7.89 & 20.72 & 2.73 & 0.25 & 0.66 & 0.09 \\
\hline \multicolumn{3}{|c|}{ Average } & 23.76 & 21.24 & 8.69 & 9.71 & 2.83 & 0.41 & 0.45 & 0.14 \\
\hline
\end{tabular}

Daytime energy balance relationship over post Aman harvested fallow rice fields

Daytime energy balance components over post Aman fallow rice field of the experimental plot on different conditions were shown in Table 3. There was variation in $R s$ mainly due to weather conditions and also higher due to seasonal variations. Sensible heat fluxes accounted for a large portion of $R n$ as it was expected from less crop canopy and less soil water availability. Sensible heat flux density of the fallow rice field just after rice harvest and showed highest 25.66 $\mathrm{MJm}^{-2}$ (Table 3). On an average, $H$ was $58.6 \%$ of the whole $R n$ just after harvesting of the Aman rice and also observed that a minimum $H$ of $5.68 \%$ and maximum of $114.86 \%$ in well irrigated fields and there were also measured $H / R n$ ratios from the rice field was maximum $0.79 \mathrm{MJm}^{-2}$, minimum $0.07 \mathrm{MJm}^{-}$ ${ }^{2}$ and on an average $0.54 \mathrm{MJm}^{-2}$. The $l E$ was positive during the day with few fluctuations and observed 5$65 \%$ of the $R n$ partitioned to $l E$ for post Aman rice fallow field. There also measured $l E / R n$ ratios from the rice field and observed that the maximum 0.76 $\mathrm{MJm}^{-2}$, minimum $0.05 \mathrm{MJm}^{-2}$ and on an average 0.30 $\mathrm{MJm}^{-2}$. $G / R n$ accounted maximum $0.24 \mathrm{MJm}^{-2}$, minimum $0.07 \mathrm{MJm}^{-2}$ and on an average $0.16 \mathrm{MJm}^{-}$ ${ }^{2}$ and $G$ was considerably larger than vegetative fields due to the less crop canopy architecture in post Aman rice fallow field.

Table 3: Day time (6:00h to 18:00h) energy balance of different fallow periods of post Aman harvested rice field. It includes different weather parameters (Air temperature, relative humidity and wind speed), incoming solar radiations $(R s)$, net radiations $(R n)$, latent heat fluxes $(l E)$, sensible heat fluxes $(H)$ and soil heat fluxes $(G)$. Ratios of latent heat fluxes and soil heat fluxes to net radiation are also included.

\begin{tabular}{|c|c|c|c|c|c|c|c|c|c|c|}
\hline \multirow[t]{2}{*}{ Seasons } & \multirow[t]{2}{*}{ Field Status } & \multirow[t]{2}{*}{ DOY } & $R s$ & $R n$ & $l E$ & $H$ & $G$ & $l E / R n$ & $H / R n$ & $G / R n$ \\
\hline & & & \multicolumn{8}{|c|}{$\frac{1}{\mathrm{MJ} / \mathrm{m}^{2}}$} \\
\hline \multirow{9}{*}{ 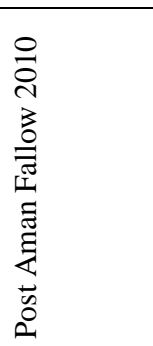 } & \multirow[t]{3}{*}{ Just after Harvest } & 306 & 18.85 & 17.60 & 4.15 & 12.15 & 1.30 & 0.24 & 0.69 & 0.07 \\
\hline & & 307 & 36.96 & 32.28 & 4.22 & 25.66 & 2.40 & 0.13 & 0.79 & 0.07 \\
\hline & & 308 & 38.71 & 32.61 & 7.37 & 23.04 & 2.20 & 0.23 & 0.71 & 0.07 \\
\hline & \multirow{3}{*}{ Post Aman fallow } & 336 & 29.57 & 23.82 & 5.67 & 12.59 & 5.56 & 0.24 & 0.53 & 0.23 \\
\hline & & 337 & 31.24 & 26.25 & 1.34 & 18.95 & 5.96 & 0.05 & 0.72 & 0.23 \\
\hline & & 338 & 31.53 & 26.56 & 4.24 & 16.04 & 6.28 & 0.16 & 0.60 & 0.24 \\
\hline & \multirow{3}{*}{$\begin{array}{c}\text { Just before } \\
\text { Transplantig }\end{array}$} & 2 & 25.26 & 18.69 & 14.30 & 1.27 & 3.13 & 0.76 & 0.07 & 0.17 \\
\hline & & 3 & 20.28 & 13.82 & 5.21 & 5.76 & 2.86 & 0.38 & 0.42 & 0.21 \\
\hline & & 4 & 11.77 & 9.43 & 5.01 & 2.74 & 1.67 & 0.53 & 0.29 & 0.18 \\
\hline \multicolumn{3}{|c|}{ Average } & 27.13 & 22.34 & 5.72 & 13.13 & 3.48 & 0.30 & 0.54 & 0.16 \\
\hline
\end{tabular}

\section{Daytime energy balance relationship over rice field on Boro 2011}

Daytime energy balance components over Boro rice field of the experimental plot on different growth stages of rice were shown in Table 4. Variations in $R s$ mainly observed due to weather condition. On an average, $l E\left(8.91 \mathrm{MJ} / \mathrm{m}^{2}\right)$ and $H\left(15.61 \mathrm{MJ} / \mathrm{m}^{2}\right)$ was accounted similar in the Boro rice field due weather conditions. There also measured $H / R n$ ratios from the rice field and observed maximum $0.88 \mathrm{MJm}^{-2}$, minimum $0.32 \mathrm{MJm}^{-2}$ and on an average $0.49 \mathrm{MJm}^{-2}$, this phenomenon due to seasonal weather characteristics. The $l E\left(15.14 \mathrm{MJ} / \mathrm{m}^{2}\right)$ observed larger in full growth stage and $H\left(31.58 \mathrm{MJ} / \mathrm{m}^{2}\right)$ observed 
larger in crop maturation stage (Table 4). The $l E / R n$ ratios in the Boro rice field observed maximum 0.45 $\mathrm{MJm}^{-2}$, minimum $0.04 \mathrm{MJm}^{-2}$ and on an average 0.35 $\mathrm{MJm}^{-2}$. $G$ accounted maximum $0.22 \mathrm{MJm}^{-2}$, minimum
$0.08 \mathrm{MJm}^{-2}$ and on an average $0.15 \mathrm{MJm}^{-2}$ and $G$ was considerably small due to the canopy architecture Boro rice cropping system.

Table 4: Day time (6:00h to 18:00h) energy balances of different growth stages of Boro rice field. It includes different weather parameters (Air temperature, relative humidity and wind speed), incoming solar radiations $(R s)$, net radiations $(R n)$, latent heat fluxes $(l E)$, sensible heat fluxes $(H)$ and soil heat fluxes $(G)$. Ratios of latent heat fluxes and soil heat fluxes to net radiation are also included.

\begin{tabular}{|c|c|c|c|c|c|c|c|c|c|c|}
\hline \multirow[t]{2}{*}{ Seasons } & \multirow[t]{2}{*}{ Field Status } & \multirow[t]{2}{*}{ DOY } & $\boldsymbol{R S}$ & $R n$ & $l E$ & $\boldsymbol{H}$ & $G$ & $l E / R n$ & $H / R n$ & $G / R n$ \\
\hline & & & \multicolumn{8}{|c|}{$\mathrm{MJ} / \mathrm{m}^{2}$} \\
\hline \multirow{9}{*}{ 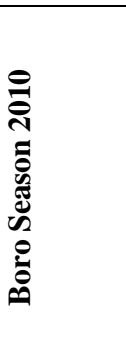 } & \multirow{3}{*}{$\begin{array}{l}\text { Early growth } \\
\text { stage }\end{array}$} & 21 & 28.02 & 23.79 & 9.14 & 9.58 & 5.07 & 0.38 & 0.40 & 0.21 \\
\hline & & 22 & 28.68 & 24.34 & 9.98 & 8.94 & 5.41 & 0.41 & 0.37 & 0.22 \\
\hline & & 23 & 23.98 & 19.84 & 9.01 & 6.37 & 4.46 & 0.45 & 0.32 & 0.22 \\
\hline & \multirow{3}{*}{$\begin{array}{l}\text { Full growth } \\
\text { stage }\end{array}$} & 81 & 40.58 & 32.87 & 15.14 & 12.92 & 4.81 & 0.46 & 0.39 & 0.15 \\
\hline & & 82 & 35.88 & 29.38 & 12.46 & 12.92 & 4.00 & 0.42 & 0.44 & 0.14 \\
\hline & & 83 & 34.63 & 29.25 & 11.25 & 14.46 & 3.53 & 0.38 & 0.49 & 0.12 \\
\hline & \multirow{3}{*}{$\begin{array}{l}\text { Mature crop } \\
\text { Before } \\
\text { Harvesting }\end{array}$} & 110 & 42.81 & 35.91 & 1.60 & 31.58 & 2.74 & 0.04 & 0.88 & 0.08 \\
\hline & & 111 & 38.15 & 31.12 & 6.12 & 22.06 & 2.94 & 0.20 & 0.71 & 0.09 \\
\hline & & 112 & 37.62 & 30.80 & 5.53 & 22.52 & 2.76 & 0.18 & 0.73 & 0.09 \\
\hline & \multicolumn{2}{|l|}{ Average } & 34.48 & 28.59 & 8.91 & 15.71 & 3.97 & 0.32 & 0.53 & 0.15 \\
\hline
\end{tabular}

\section{Daytime energy balance relationship over post Boro harvested fallow rice fields}

Daytime energy balance components over post Boro fallow rice field of the experimental plot on different conditions are shown in Table 5. There was variation in $R s$ mainly due to weather conditions and also highest due to seasonal variations. Latent heat fluxes accounted for a large portion of $R n$ as it was expected from less crop canopy and sufficient soil water availability. Latent heat flux density of the post Boro fallow rice field showed highest $31.03 \mathrm{MJm}^{-2}$. On an average, $l E$ was $40.74 \%$ of the whole Rnon post Boro Fallow rice field and also observed that a minimum $l E$ of $15 \%$ and maximum of $93 \%$ in irrigated fields. The $H$ was positive during the day with few fluctuations and observed 2-44\% of the $R n$ partitioned to $H$ for post Boro rice fallow field (Table $5)$. There also measured $l E / R n$ ratios from the rice field and observed maximum $0.82 \mathrm{MJm}^{-2}$, minimum $0.41 \mathrm{MJm}^{-2}$ and on an average $0.66 \mathrm{MJm}^{-2}$ and $l E / R n$ exhibits the highest ratios among the all observation periods and due to more availability of water. The $H / R n$ ratios observed maximum $0.50 \mathrm{MJm}^{-2}$, minimum $0.12 \mathrm{MJm}^{-2}$ and on an average $0.25 \mathrm{MJm}^{-2}$. $G$ accounted maximum $0.14 \mathrm{MJm}^{-2}$, minimum 0.06 $\mathrm{MJm}^{-2}$ and on an average $0.09 \mathrm{MJm}^{-2}$ and $G$ was considerably smaller than vegetative fields due to the less crop canopy architecture and much water availability in post Boro rice fallow field.

Table 5: Day time (6:00h to 18:00h) energy balances of different fallow periods of post Boro harvested rice field. It includes different weather parameters (Air temperature, relative humidity and wind speed), incoming solar radiations $(R s)$, net radiations $(R n)$, latent heat fluxes $(l E)$, sensible heat fluxes $(H)$ and soil heat fluxes $(G)$. Ratios of latent heat fluxes and soil heat fluxes to net radiation are also included.

\begin{tabular}{|c|c|c|c|c|c|c|c|c|c|c|}
\hline \multirow[t]{2}{*}{ Seasons } & \multirow[t]{2}{*}{ Field Status } & \multirow[t]{2}{*}{ DOY } & $R s$ & $R n$ & $l E$ & $\boldsymbol{H}$ & $\boldsymbol{G}$ & $l E / R n$ & $H / R n$ & $G / R n$ \\
\hline & & & \multicolumn{8}{|c|}{$\mathrm{MJ} / \mathrm{m}^{2}$} \\
\hline \multirow{9}{*}{ 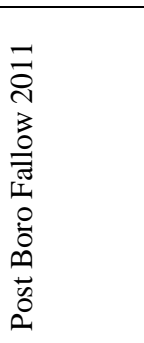 } & \multirow[t]{3}{*}{ Just after Harvest } & 122 & 43.98 & 34.32 & 21.10 & 10.21 & 3.01 & 0.61 & 0.30 & 0.09 \\
\hline & & 123 & 35.44 & 28.51 & 11.70 & 14.38 & 2.43 & 0.41 & 0.50 & 0.09 \\
\hline & & 124 & 33.89 & 26.66 & 13.87 & 9.17 & 3.62 & 0.52 & 0.34 & 0.14 \\
\hline & \multirow[t]{3}{*}{ Post Boro fallow } & 153 & 43.36 & 37.91 & 31.03 & 4.78 & 2.11 & 0.82 & 0.13 & 0.06 \\
\hline & & 154 & 40.19 & 33.06 & 21.73 & 7.84 & 3.49 & 0.66 & 0.24 & 0.11 \\
\hline & & 155 & 37.87 & 32.17 & 20.69 & 8.62 & 2.86 & 0.64 & 0.27 & 0.09 \\
\hline & \multirow{3}{*}{$\begin{array}{l}\text { Just before } \\
\text { Transplantig }\end{array}$} & 183 & 19.55 & 16.07 & 11.93 & 2.63 & 1.52 & 0.74 & 0.16 & 0.09 \\
\hline & & 184 & 8.63 & 6.74 & 5.18 & 0.81 & 0.74 & 0.77 & 0.12 & 0.11 \\
\hline & & 185 & 19.68 & 17.47 & 12.96 & 3.13 & 1.38 & 0.74 & 0.18 & 0.08 \\
\hline \multicolumn{3}{|c|}{ Average } & 31.40 & 25.88 & 16.69 & 6.84 & 2.35 & 0.66 & 0.25 & 0.09 \\
\hline
\end{tabular}


After the harvest of Aman rice, on the fallow period $l E$ showed a slight decrease on an average 2.97 $\mathrm{MJ} / \mathrm{m}^{2}$, which was the resultant of the decreasing transpiration rate of rice plants. On the post Aman fallow rice field $H$ increased, on an average 3.42 $\mathrm{MJ} / \mathrm{m}^{2}$ than Aman rice. Positive $H$ indicated release of sensible heat to upper air, which provided energy for $l E$ and this is due less crop canopy architecture and less water availability on the fallow rice field. The $G / R n$ ratio slightly decreased when the canopy became a bit sparse from its previous condition.

In case of Boro rice, during the fallow period, $l E$ showed a slight increase on an average $3.31 \mathrm{MJ} / \mathrm{m}^{2}$, which was the result of the increasing transpiration rate from miscellaneous weeds from the rice field community and much water availability on the field. On post Boro fallow rice field $H$ was also increase on an average $0.61 \mathrm{MJ} / \mathrm{m}^{2}$ than Boro rice.

From the result it is apparent that on Boro 2011 rice field showed slightly increase of $l E$ than the Aman 2010 rice field and on post Boro fallow, rice field showed increased of $l E$ than post Aman fallow rice field, which was a clear deviation from the previous results. This might be due to the long sunshine hour, much water availability in the field that occurred prior to the observed period. According to Ham et al. (1991) $l E$ partitioning tends to increase as the soil moisture is not limiting. $H$ was still positive during the daytime. Decreased G was observed as a result of surface cooling due to the increased evaporation of soil moisture after the rain.

\section{Acknowledgements}

The authors deeply acknowledge the National Institute for Agro-Environmental Sciences (NIAES), Tsukuba, Japan; Japan Society for the Promotion of Science (JSPS) and University Grants Commission of Bangladesh (UGC), Dhaka and Bangladesh Agricultural University Research System (BAURES), Bangladesh Agricultural University, Mymensingh for providing financial support and research facilities for conducting the entire research work with utmost cooperation.

\section{References}

Arya, P. S. 2001. Introduction to Micrometeorology. Second Edition.Academic Press.A Harcourt Science and Technology Company, Harcourt place, 32 Jamestown Road, London NWI 7BY, UK.pp.11-13.
Baldocchi, D. D.; Xu, L. K. and Kiang, N. 2004. How plant functional-type, weather, seasonal drought, and soil physical properties alter water and energy fluxes of an oak-grass savanna and an annual grassland. Agric. For. Meteorol., 123:13-39.

Bangladesh Bureau of Statistics. 2010. Summary Crop Statistics-Area, Yield Rates and Productions of Major Crops 2007-2008, 2008-2009 and 2009-2010. Online: 10.09.2011.Availablefrom:http://www.bbs.g ov.bd/WebTestApplication/userfiles/Image/ AgricultureCensus/All_Crops_summary_0910.pdf.

Baten, M. A. and Kon, H. 1997. Comparisons of solar radiation interception, albedo and net radiation as influenced by row orientation of crops. J. Agric. Metero., 53(1): 29-39.

Ham, J. M.; Heilman, J. L. and Laseanao, R. J. 1991. Soil and canopy energy balances of a row crop at partial cover. Agron. J., 83: 744-753.

Kirschbaum, M.U.F., 1995. The temperature dependence of soil organic matter decomposition and the effect on global warming on soil organic C storage. Soil Biol. Biochem. 27, 753-760.

Li, S. G.; Eugster, W. Asanuma, J.; Kotani, A.; Davaa, G.; Oyunbaatar, D. and Sugita, M. 2006. Energy partitioning and its biophysical controls above a grazing steppe in central Mongolia. Agricultural and Forest Meteorology.,137;89-106.

Liang, N. S., Nakadai, T., Hirano, T., Qu, L.Y., Koike, T., Fujinuma, Y., Inoue, G., 2004. In situ comparison of four approach approaches to estimating soil $\mathrm{CO} 2$ efflux in a northern larch (LarixkaempferiSarg.) forest. Agric. For. Meteorol., 123, 97-117.

UNDP (United Nations Development Program) and FAO (Food and Agriculture Organization), 1998. Land Resources Appraisal of Bangladesh for Agricultural Development. Report 2. Agro-ecological Regions of Bangladesh. UNDP, FAO, Rome. pp116. 